Ziolkowski, A. M., Parkes, G. E., Hatton, L., \& Haugland, T. (1982). The signature of an air-gun array: computation from near-field measurements. Geophysics 47, 1413-1421.

\title{
AIR GUN ARRAYS AS NOISE SOURCES: OUTPUT, IMPACT ZONES, AND FREQUENCY CONTENT
}

\author{
PETER T. MADSEN \\ Department of Biological Sciences, University of Aarhus, Building 1131, \\ 8000 Aarhus C, Denmark; Woods Hole Oceanographic Institution, Woods Hole, \\ MA 02543, USA. peter.madsen@biology.au.dk
}

\section{INTRODUCTION}

The widespread use of powerful, low-frequency air gun pulses for seismic seabed exploration has raised concern about their potential negative effects on marine wildlife. An array of air guns creates a downward-directed, low-frequency pulse with most energy concentrated around $50 \mathrm{~Hz}$ and a back-calculated, broadband source level between 230 and $260 \mathrm{~dB}$ re $1 \mathrm{\mu Pa}(0$ peak) with ocean-traversing potential. This talk reports the sound exposure levels recorded on acoustic tags attached to eight sperm whales at ranges between 1.4 and $12.6 \mathrm{~km}$ from controlled air gun array sources operated in the Gulf of Mexico and discusses the implications for sound metrics, exposure zones, and impacts on marine mammals.

\section{METHODS}

During 6 weeks of field work as a part of the Sperm Whale Seismic Study (SWSS) Gulf of Mexico cruises in 2002 and 2003, we tagged 8 sperm whales with Dtags. The whales were tracked acoustically and visually for 1-2 hours before playbacks with full-scale air gun arrays using a ramp-up procedure. A noninvasive, archival Dtag was used to gather data on 3-D movements and sounds impinging on or produced by the tagged whale. Movements of the tagged whales were logged by a depth sensor and 3-axis magnetometers and accelerometers sampled at $50 \mathrm{~Hz}$, while absolute sound pressure levels could be computed from audio recordings in the frequency range from 45 to $12,000 \mathrm{~Hz}$. Acoustic data were analyzed in Matlab. Whale location between sightings with respect to the noise source was later estimated using dead reckoning based on the orientation sensors, and estimated ranges between source and whale were considered to be accurate within $\pm 0.5 \mathrm{~km}$. 


\section{RESULTS}

Due to multipath propagation, the animals were all exposed to multiple sound pulses during each firing of the array with received $\mathrm{m}$-weighted sound levels for each of the analyzed pulses between 131 and $167 \mathrm{~dB}$ re $1 \mu \mathrm{Pa}$ (peak to peak; $100-135 \mathrm{~dB}$ re $1 \mu \mathrm{Pa}^{2}$ s). A complex pattern of multiple arrivals was seen in all exposure events that could be analyzed, and it is evident that each firing of the array leads to exposure of the whale by several pulses with differing temporal and spectral properties. In particular, high-frequency components with the most energy between 500 and $3,000 \mathrm{~Hz}$ were found in some of the exposures of all whales, showing that air gun arrays generate highfrequency by-products (Figure 1) (Madsen et al. 2006). The exposure patterns could not be explained by simple geometric spreading laws, but more complex propagation models accounting for a varying sound velocity profile have successfully modelled the sound exposures (DeRuiter et al. 2006).

\section{DISCUSSION}

Different metrics to quantify sound exposures constitute a potential source of misunderstandings and abuse. I argue against the use of RMS measures for transients and advocate that transient noise exposure is reported in peak-to-peak sound pressure levels and energy flux density (Madsen 2005). The highest sound pressure of $167 \mathrm{~dB}$ re $1 \mu \mathrm{Pa}$ (peakto-peak) received by a sperm whale at $1.4 \mathrm{~km}$ most likely excludes any temporary or permanent hearing loss at these and longer ranges from an operating air gun array. However, for other impact zones such as those of detection and behavioural disruption, the complex sound propagation in deep stratified water renders geometric-spreading models useless because the whales may be exposed to the same levels at 2 and $12 \mathrm{~km}$ from the array. Some air gun arrays generate significant sound energy at frequencies many octaves higher than what the arrays are designed for (Figure 1) where the potential impact on toothed whales with poor low-frequency hearing is more severe (Madsen et al. 2006). The transient nature of air gun pulses makes their masking potential very small, but future studies need to address the behavioural effects of air gun exposures with received levels between 140 to $170 \mathrm{~dB}$ re $1 \mu \mathrm{Pa}$ (peak-to-peak) on naïve animals and investigate how potential mitigation in a complex sound field can be implemented using better measures of sound radiation patterns from air gun arrays in deep water. 

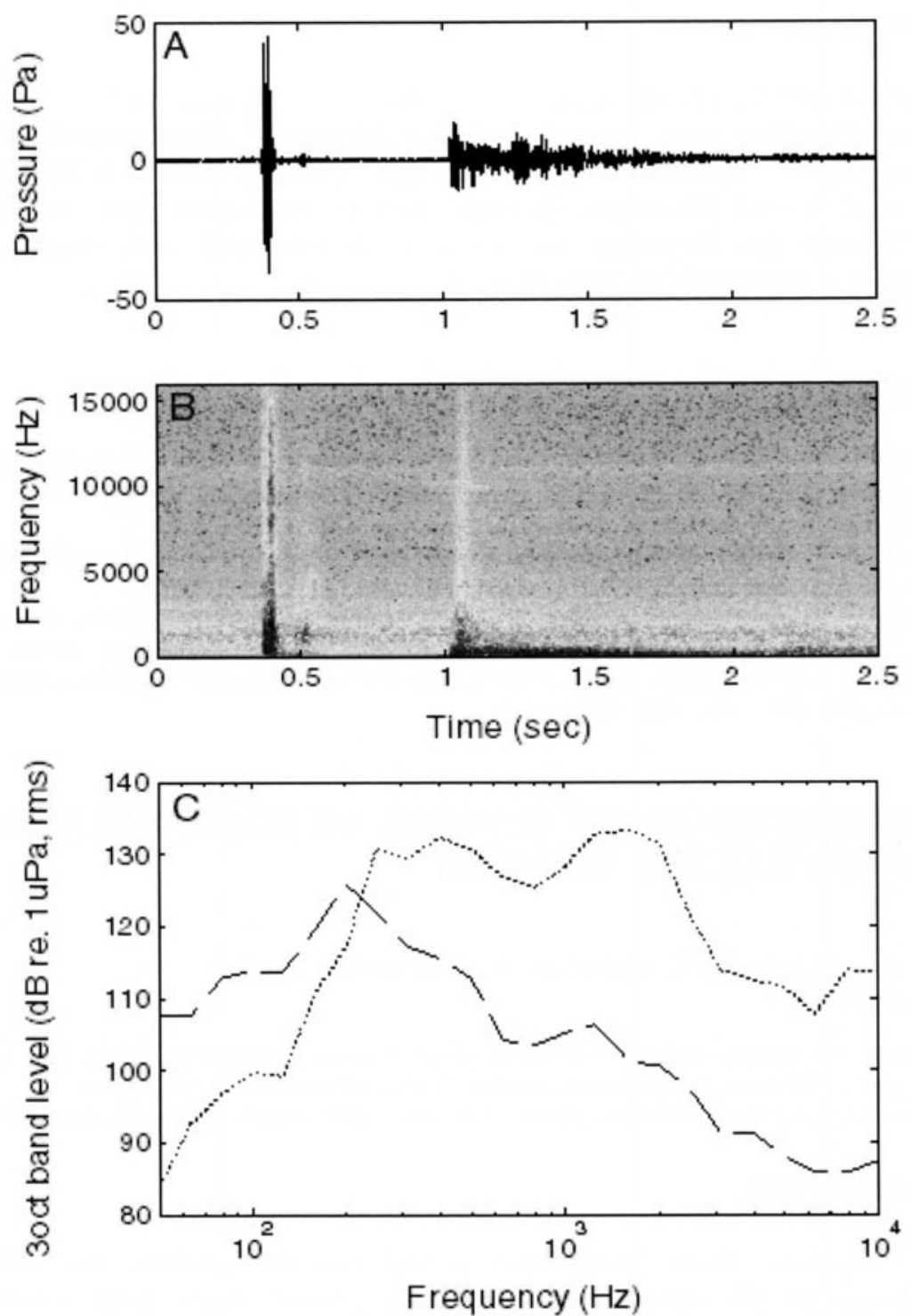

Figure 1. (A) Waveform of an air gun exposure of whale sw03_173b at a range of $3 \mathrm{~km}$ and a depth of 15 meters. (B) Spectrogram of the waveform in (A) $(\mathrm{FFT}=1024,50 \%$ overlap). Note how the first pulse arrival has energy all the way up to the Nyquist frequency, whereas the second arrival has little energy above $1 \mathrm{kHz}$. (C) Third-octave $\mathrm{rms}$ sound pressure levels of the two pulses displayed in (A) and (B). First arrival has a dotted line and the second arrival has a dashed line. The rms levels can be converted to thirdoctave SELs ( $\mathrm{dB}$ re $1 \mu \mathrm{Pa}^{2} \mathrm{~s}$ ) by subtracting $13 \mathrm{~dB}$ (54 ms duration) for the rms levels of the first pulse and $7 \mathrm{~dB}$ (200 ms max integration time) for the rms levels of the second pulse (Madsen et al. 2006). 


\title{
ACKNOWLEDGMENTS
}

Thanks to P. Tyack, M. Johnson, P. Miller, N. Aguilar de Soto, and ship crews. Funding was provided under Minerals Management Service Cooperative Agreements 1435-01-02-CA-85186 and NA87RJ0445, Office of Naval Research Grants N00014-99-1-0819 and N00014-0210187, and the Strategic Environmental Research and Development Program Grant D8CA7201C0011.

\section{REFERENCES}

Deruiter S., Tyack P. L., Lin Y.-T., Newhall A., Lynch J., \& Miller P. (2006). Modeling acoustic propagation of airgun array pulses recorded on tagged sperm whales (Physeter macrocephalus). J. Acoust. Soc. Am. 120, 2366-2379.

Madsen, P. T. (2005). Marine mammals and noise: what is a safety level of $180 \mathrm{~dB}$ re $1 \mu \mathrm{Pa}$ (rms) for transients? J. Acoust. Soc. Am. 117, 3952-3957.

Madsen, P. T., Johnson, M., Miller, P. J. O., Aguilar de Soto, N., Lynch, J., \& Tyack, P. L. (2006). Quantitative measures of air gun pulses recorded on sperm whales Physeter macrocephalus, using acoustic tags during controlled exposure experiments. J. Acoust. Soc. Am. 120, 4100-4114.

\section{TRANSMISSION OF MARINE SEISMIC SIGNALS IN AUSTRALIAN WATERS}

\author{
R. D. MCCAULEY ${ }^{1}$, S. R. RENNIE 2 , J. R. HUGHES ${ }^{3}$, AND \\ A. J. DUNCAN ${ }^{4}$ \\ ${ }^{1,2,4}$ Centre for Marine Science and Technology, Curtin University, G.P.O. Box U 1987, \\ Perth 6845, Western Australia, Australia.1'r.mccauley@cmst.curtin.edu.au \\ ${ }^{3}$ Santos Ltd., 91 King William Street, Adelaide 5000, South Australia, Australia.
}

\section{INTRODUCTION}

With support from Australian petroleum companies, we collected in excess of 28 sets of seismic transmission data from sources of 20 to 4,900 cui plus characterised air gun array sources. This work underpins new Australian seismic and marine mammal guidelines.

\section{METHODS}

Sea noise loggers (see www.cmst.curtin.edu.au for specifications) were placed on the seafloor in regions where seismic surveys have taken place since 2000. Loggers record with a several kilohertz useable 